\title{
Comparison of Components and Anti-Liver Cancer Activity In vitro between Huanglian and Yunlian
}

\author{
Chingshan To ${ }^{1}$, Caylan Liew ${ }^{1,2}$, Xuanbin Wang ${ }^{1,3}$, Ning Wang ${ }^{1}$ and Yibin Feng ${ }^{1 *}$
}

${ }^{1}$ School of Chinese Medicine, The University of Hong Kong, China

${ }^{2}$ Chemical and Biological Sciences, Polytechnic Institute of New York University, USA

${ }^{3}$ Laboratory of Chinese Herbal Pharmacology, Renmin Hospital, Hubei University of Medicine, Shiyan, P. R. China, 442000

\begin{abstract}
Objective: Coptidis Rhizoma is a famous Chinese medicinal herb for its potential to combat cancer, inflammation, fibrosis, viral and bacterial infections, and oxidation. Coptis chinensis Franch (Huanglian in Chinese HL) and Coptis teeta Wall (Yun Huanglian or Yunlian YHL) are two species of Coptidis Rhizoma commonly used in Traditional Chinese Medicine. Huanglian is produced from Sichuan Province, while Yunlian comes from the Yunnan Province. Both provinces are located in China. There are indications that both herbs possess similar characteristics and functions in clinical use. However, there are no signs of prior research to compare the effects of $\mathrm{HL}$ and $\mathrm{YHL}$ on hepatocellular carcinoma. In this study, we compared the components and anti-liver cancer effects in vitro between Huanglian and Yunlian.
\end{abstract}

Methods: HPLC was introduced to analyze the active components in Huanglian and Yunlian aqueous extracts. Liquid chromatography with mass spectrometry and High performance liquid chromatography with UV detector were used to identify and compare the main ingredients ratio between Huanglian and Yunlian extracts. Cytotoxicity and apoptosis affected by the two extracts on MHCC97L cell line was observed by using MTT assay and flow cytometry, respectively. The inhibition of metastasis and invasion in hepatocellular carcinoma cell line MHCC97L by Huanglian and Yunlian were compared as well.

Results: Results of phytochemical analysis showed there were no significant differences between the two herbs' ingredients and ratios. Also, there were no significant differences between Huanglian and Yunlian on cytotoxicity, apoptosis and metastasis in MHCC97L.

Conclusion: Yunlian and Huanglian share great similarities in both chemical compostion and bioactivity in vitro.

Keywords: Coptidis rhizoma; Coptis chinensis Franch (Huanglian); Coptis teeta Wall (Yunlian); Quality control; Quantity control; Cytotoxicity; Metastasis

\section{Introduction}

Since antiquity, Coptidis Rhizoma (Coptis) has been administered as an ancient remedy. In Traditional Chinese Medicine (TCM), coptis is used to treat conditions associated with Qingre Zaoshi (clearing heat and removing dampness), Xiehuo Jiedu (purging fire to eliminate toxin) such as diarrhea, eye inflammation and women's abdomen ailments $[1,2]$. Recent studies have disclosed its potential to combat cancer, inflammation, fibrosis, viral and bacterial infections, and oxidation [310]. Coptis and its main ingredient, berberine, show significant effects on cancer with a multiple targets including mitochondrial [11], NAG-1 $[12,13]$, topoisomerases [14], estrogen receptors [15], p53 [16,17], NF$\kappa \mathrm{B}[18,19]$ and ROS [20]. Our previous studies indicated that Coptis extracts activated miR-21 and miR-23a in human liver cancer [21], we also found that Coptis and berberine initiated autophagy in liver cancer by activating Beclin-1 and blocking mTOR-signaling way by suppressing the activity of Akt and inducing p38 MAPK activation [22].

According to China Pharmacopoeia (2010), three species could be the resources of Coptis, including Coptis chinensis Franch, Coptis deltoidea C.Y. Cheng et Hsiao and Coptis teeta Wall [23], among which Coptis chinensis Franch (Huanglian in Chinese, HL) and Coptis teeta Wall (Yun Huanglian or Yunlian, YHL) are two main medical products from Sichuan Province and Yunnan Province, respectively. Chemical analysis have determine Berberine to be Huanglian's active components, and other trace alkaloids include palmatine, columbamine, jatrorhizine, epiberberine, copsitine, and an aporphinoid alkaloid-magnoflorine [24]. However, it shall be necessary to provide scientific evidence to show the bioequivalence of $\mathrm{HL}$ and YHL in certain pharmacoligcal aspects.

In this study, we compared the chemical compositions and tumor suppressive effects in vitro between Huanglian and Yunlian. High performance liquid chromatography (HPLC) and HPLC combined with mass spectrometry (LC-MS) were facilitated to determine berberine and other alkaloids and their ratio. As we previously found that berberine effectively inhibited cell migration and invasion at low doses by induction of Rho GTPases including RhoA, Cdc42 and Rac1 [25]. Inhibition of huanglian and yunlian on migration and invasion in human hepatocellular carcinoma cell line MHCC97L was investigated in this study as well.

\section{Materials and Methods}

\section{Preparation of HL and YHL Aqueous Extracts}

Dried HL and YHL herbs were collected from Sichuan and Yunnan

*Corresponding author: Yibin Feng, School of Chinese Medicine, The University of Hong Kong, 10 Sassoon Road, Pokfulam, Hong Kong, China, Tel: 852 25890482; Fax: 852-28725476; E-mail: yfeng@hku.hk

Received July 03, 2012; Accepted August 11, 2012; Published August 16, 2012

Citation: To C, Liew C, Wang X, Wang N, Feng Y (2012) Comparison of Components and Anti-Liver Cancer Activity In vitro between Huanglian and Yunlian. J Bioequiv Availab 4: 086-090. doi:10.4172/jbb.1000118

Copyright: (c) 2012 To C, et al. This is an open-access article distributed under the terms of the Creative Commons Attribution License, which permits unrestricted use, distribution, and reproduction in any medium, provided the original author and source are credited. 
Province of China respectively and authenticated under the guidance of Chinese Pharmacopoeia (2010). They were identified by School of Chinese medicine, the University of Hong Kong. $500 \mathrm{~g}$ of each was boiled in 10 times of distilled water $(\mathrm{w} / \mathrm{v})$ at $100^{\circ} \mathrm{C}$ for 1 hour and percolated through filter paper (Whatman, pleated filter grade 597 1/2, 4-7 $\mu \mathrm{m}$ ) and then sterilized by filtration through a $0.2 \mu \mathrm{m}$ pore filter (Minisart ${ }^{\circledR}$-plus, Sartorius). The filtrate was further concentrated and the dry extract powder was collected and stored at $-20^{\circ} \mathrm{C}$ until used.

\section{Cell line}

Human hepatocellular carcinoma cell line MHCC97L was kindly gifted by Dr. Man Kwan, Department of Surgery, and The University of Hong Kong. Cells were cultured in DMEM medium (Invitrogen, USA), and incubated in a humidified atmosphere containing $5 \% \mathrm{CO}_{2}$ at $37^{\circ} \mathrm{C}$.

\section{Identification of chemical composition of $\mathrm{HL}$ and YHL extracts by LC-MS}

LC-MS (Thermo Finnigan, USA) was used to identify the chemical composition of HL and YHL extracts. Both HL and YHL extract powders were dissolved in methanol and diluted to proper concentration. $10 \mu \mathrm{l}$ of sample solution was injected to the LC-MS [26-28].

\section{Quantification of active components of $\mathrm{HL}$ and YHL extracts by HPLC}

HPLC (Water 996 Photodiode Array Detector, Waters 717plus Autosampler, Water 600S Controller, Empower Pro Analysis system, USA) was introduced to analyze the active components in herb extracts as described previously [29-31].

\section{Cell viability assay}

In vitro cytotoxicity of $\mathrm{HL}$ and YHL extracts on MHCC97L cells was observed using MTT (3-[4,5-dimethylthiazol-2-yl]-2,5-diphenyl tetrazolium bromide) assay system. $1 \times 10^{4}$ cells with $100 \mu \mathrm{l}$ of medium per well were seeded in 96-well plates, incubated, and treated with different concentrations of HL and YHL for 24, 48, and $72 \mathrm{hrs,}$ respectively. At the end of each treatment, $10 \mu \mathrm{l}$ of MTT $(5 \mathrm{mg} / \mathrm{mL})$ was added to the well and incubated for $4 \mathrm{hrs}$. The absorbance was read at $575 \mathrm{~nm}$ with Multiskan MS microplate reader (Labsystems, Finland).

\section{Annexin v/PI staining}

Cells were seeded in 35-mm petri-dish with $80 \%$ confluence and treated with different concentrations of HL and YHL for $24 \mathrm{hrs}$. After treatment, cells were collected using micro-scraper (Corning, USA) and then centrifuged. To detect apoptosis in MHCC97L cells, Annexin V/PI double staining kit (Sigma-aldrich, USA) was introduced to quantify cell amount in different stages of cell death. Briefly, cells were resuspended in $1 \mathrm{~mL}$ of binding buffer containing $100 \mathrm{mM}$ HEPES/ $\mathrm{NaOH}, 1.4 \mathrm{M} \mathrm{NaCl}, 25 \mathrm{mM} \mathrm{CaCl}_{2}, \mathrm{pH}$ 7.5. Then $5 \mu$ of FITC-conjugated Annexin $\mathrm{V}(50 \mu \mathrm{g} / \mathrm{mL})$ and $10 \mu \mathrm{l}$ of propidium iodide $(100 \mu \mathrm{g} / \mathrm{mL})$ were added to the cell suspension. Incubation of cells was performed in dark for exactly 10 minutes at room temperature and detected by flow cytometer (Epics XL, Beckman Coulter, USA).

\section{Wound healing assay}

MHCC97L cells were seeded in 6-well plates and waited for full confluence attained. To introduce uniform wound on the confluent monolayer cells, a gap was scraped by using a micro-pipette tip on each well. After wound introduction, culture medium was replaced with fresh medium containing different concentrations of HL and YH. To compare the speed of wound closure between berberine treated and untreated cells, photographs were taken under 100x magnifications using phase-contrast microscopy immediately after wound incision (0 h) and after $24 \mathrm{hrs}$.

\section{Invasion chamber assay}

The experiment was conducted under the manufacturer's instruction (QCMT 96-well cell invasion assay kit, Millipore, USA). Briefly, $100 \mu \mathrm{l}$ of pre-warmed serum free media was placed into the invasion chamber and the plate was incubated for 1 hour at room temperature. After rehydration of chamber, media were removed and $150 \mu \mathrm{l}$ serum free media in the presence of $10 \%$ fetal bovine serum were added to the feeder tray. $100 \mu \mathrm{l}$ serum free media with $1 \times 10^{4}$ MHCC97L cells were then placed into invasion chamber. A series of concentrations of agents were added to cell suspension and incubated for 24 hours at $37^{\circ} \mathrm{C}, 5 \% \mathrm{CO}_{2}$. Then media with cell suspension in each chamber were discarded and the chamber plate was plated onto a new feeder tray containing $150 \mu \mathrm{l}$ PBS in each well and incubated for 1 minute at room temperature. After rinsing with PBS as described, PBS was removed and $150 \mu \mathrm{l}$ of pre-warmed cell detachment solution were added to the feeder tray and the chamber plate was incubated for 30 minutes at $37^{\circ} \mathrm{C}$. This step was followed by addition of $50 \mu$ of lysis buffer/dye and 15 minutes incubation at room temperature. $150 \mu \mathrm{l}$ of the mixture was transferred to a new 96 -well black plate and read it using $480 / 520 \mathrm{~nm}$ filters set using a fluorescence plate reader.

\section{Statistical analysis}

Data was computed using student T-test and expressed as mean \pm SD. Experiments were repeated three times. $\mathrm{P}<0.05$ was considered significantly difference.

\section{Results}

\section{Identification of chemical composition in $\mathrm{HL}$ and $\mathrm{YHL}$ extracts by LC-MS}

7 peaks, magnoflorine, columbamine, jatrorhizine, epiberberine, copsitine, palmatine, and berberine were identified as major alkaloids in both HL and YHL extracts as reported previously [26,27]. No significant difference of chemical composition between HL and YHL extracts was observed (Table 1).

\section{Quantification of active components in $\mathrm{HL}$ and YHL extracts by HPLC}

Area of 5 main peaks were determined and calculated as a percentage of total area. Data indicated there was no difference between the two herbal extracts (Figure 1 and Table 1). It was shown that berberine is the major active compound in both HL and YHL. The yields of berberine in HL and YHL were $32.14 \%$ and $30.96 \%$ respectively.

\begin{tabular}{|c|c|c|c|c|c|}
\hline & Magnoflorine & Jatrorhizine & Coptisine & Palmatine & Berberine \\
\hline$\%$ in $\mathrm{HL}$ & 4.49 & 7.84 & 10.22 & 12.89 & 32.14 \\
\hline$\%$ in $\mathrm{YHL}$ & 2.33 & 4.81 & 8.21 & 9.76 & 30.96 \\
\hline
\end{tabular}

Table 1: Summary of active components in HL and YHL. The phytochemical analysis was performed under the following condition: Reserve C18 column (Symmetry ${ }^{\circledR}, 250 \mathrm{~mm} \times 4.0 \mathrm{~mm}, 5 \mu \mathrm{m}$ ) was used as solid phase; elution was performed using acetonitrile- $25 \mathrm{mM}$ potassium dihydrogen phosphate (23:77) as mobile phase. Detecting wavelength and flow rate was $254 \mathrm{~nm}$ and $1.0 \mathrm{ml} /$ min respectively. The analysis was performed under room temperature. Area of 5 main peaks were calculated as a percentage of total area. There is no significant difference between two herbs. 
Citation: To C, Liew C, Wang X, Wang N, Feng Y (2012) Comparison of Components and Anti-Liver Cancer Activity In vitro between Huanglian and Yunlian. J Bioequiv Availab 4: 086-090. doi:10.4172/jbb.1000118

\section{Cytotoxicity effects of HL and YHL extracts on MHCC97L cells}

MHCC97L cells treated with HL and YHL extracts for 24, 48 and $72 \mathrm{hrs}$ were conducted and calculated. To better examine the bioequivalence between HL and YHL, the IC50 value of HL and YHL was determined and the data was presented by showing the yield of berberine contained by the extracts. IC50 value for HL was 340, 170 and $170 \mu \mathrm{M}$ for 24,48 and 72 hours, respectively, while for YHL was 380, 150 and $180 \mu \mathrm{M}$. Both of HL and YHL extracts exhibited potent cytotoxicity on MHCC97L with a dose-dependent manner in 48 hours (Figure 2).

\section{HL- and YHL- induced apoptosis in MHCC97L Cells}

The results showed that HL and YHL significantly induced early and median apoptosis in MHCC97L cells after 24 hours treatment. The induction of apoptosis by HL and YHL was slightly enhanced in line with increased doses. There was no large difference in potency between HL and YHL for inducing apoptosis in the MHCC97L cell line (Figure $3)$.

\section{HL and YHL inhibit metastasis of MHCC97L cells by wound healing assay}

It was observed that MHCC97L cells at the opposite edges of the wounds rapidly migrated toward each other after $24 \mathrm{hrs}$ of incubation. With increasing doses, the speed of wound healing slowed down, the gap remained open, and only minimal cell proliferation on the 2 edges of the wound was observed when cells were incubated with $200 \mu \mathrm{M}$ of HL and YHL. Cell motility was remarkably inhibited with HL and YHL exposure. Photographs of cells with different treatment were taken and displayed in Figure 4.

\section{HL and YHL inhibit invasion of MHCC97L cells}

The results of chamber assay combined with MTT assay showed promising inhibitory effects of HL and YHL on the invasion of MHCC97L cell line. The results also showed that HL and YHL suppressed the metastasis of MHCC97L at the doses far lower than their IC50 values. HL and YHL showed no difference in their capability to suppress cell invasion (Figure 5).

\section{Discussion}

In Chinese Pharmacopoeia, HL and YHL belong to the same genus,

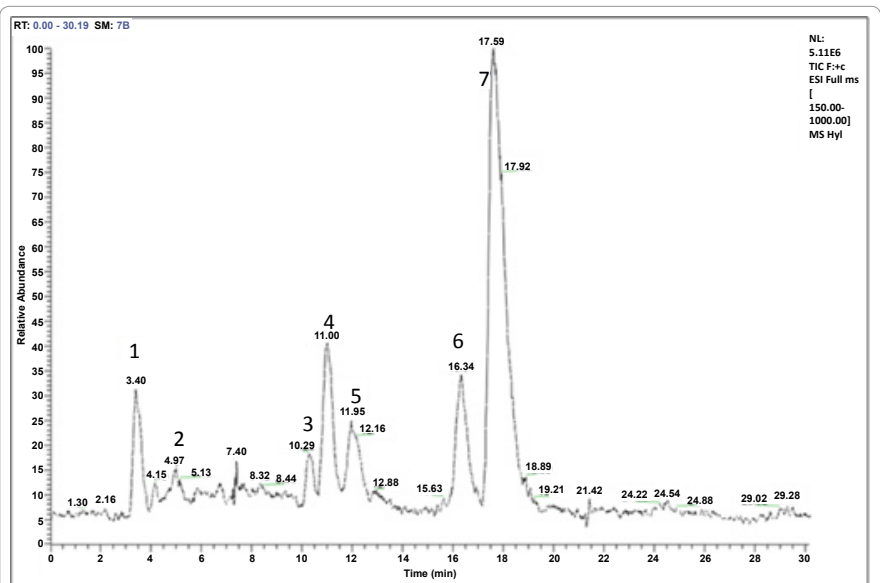

Figure 1: HPLC Chromatograms of HL extract and YHL extracts. A. HL extracts; B. YHL extracts.
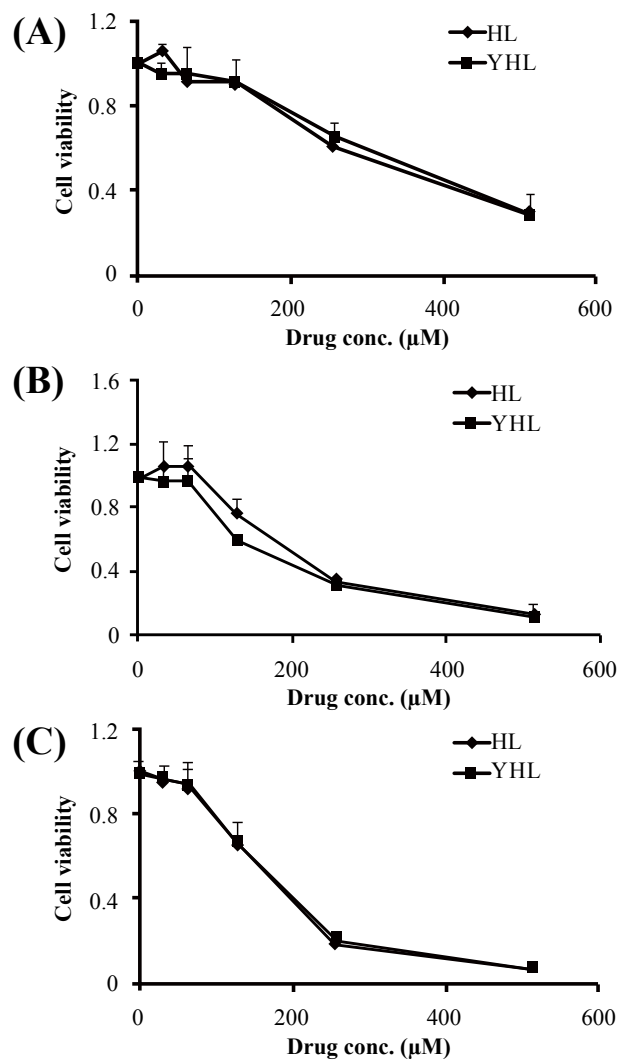

Figure 2: Viability of MHCC97L after treatments with $\mathrm{HL}$ and $\mathrm{YHL}$ for 24,48,72 hrs (Mean \pm SD). MHCC97L cells were treated with $\mathrm{HL}$ and $\mathrm{YHL}$ extracts for $24 \mathrm{~h}(\mathrm{~A}), 48 \mathrm{~h}(\mathrm{~B})$, and $72 \mathrm{~h}(\mathrm{C})$. Each concentration was tested in triplicate wells. Each experiment was repeated three times while standard deviation served as the error bars. The results showed no significant difference of effects between $\mathrm{HL}$ and $\mathrm{YHL}$ extracts $(P<0.05)$

Coptis, and both herbs could be administered in Traditional Chinese Medicine clinics, and are important components in Chinese medicine herbal formulae. There are indications that both herbs possess similar characteristics and functions in clinical use. However, there are no signs of prior research to provide any scientific observation on the pharmacological similarities of HL and YHL. In this study, we have been able to identify the active ingredients in HL and YHL by LCMS. The HPLC-UV chromatograms of HL and YHL extracts showed that there was no significant difference in the chemical composition between the two extracts. The quantification of active components in HL and YHL was obtained by HPLC where there were no remarkable variation of the yields of major active alkaloids observed between $\mathrm{HL}$ and YHL, indicating that HL and YHL share great similarities in chemical composition.

To compare the bioactivity of HL and YHL, MTT Assay and flow cytometry were employed. As we previously found that coptis and berberine effectively inhibit cell metastasis and invasion at low doses by induction of Rho GTPases including RhoA, Cdc42 and Rac1 [25]. Wound healing and invasion chamber assay were conducted to compare the inhibition of metastasis and invasion between HL and YHL. Both of HL and YHL showed similar cytotoxicity in serial concentrations. We used Annexin V/PI double-staining to monitor apoptosis induced by HL and YHL. Both HL and YHL can significantly 
Citation: To C, Liew C, Wang X, Wang N, Feng Y (2012) Comparison of Components and Anti-Liver Cancer Activity In vitro between Huanglian and Yunlian. J Bioequiv Availab 4: 086-090. doi:10.4172/jbb.1000118

induce apoptosis in MHCC97L cells after 24 hours treatment. There was no large difference in potency between HL and YHL for inducing apoptosis in the MHCC97L cell line. Wound-healing assay was introduced to qualitatively determine the migration of MHCC97L cells with exposure to HL and YHL. Cell motility was remarkably inhibited under exposure with either HL or YHL. Moreover, the results of
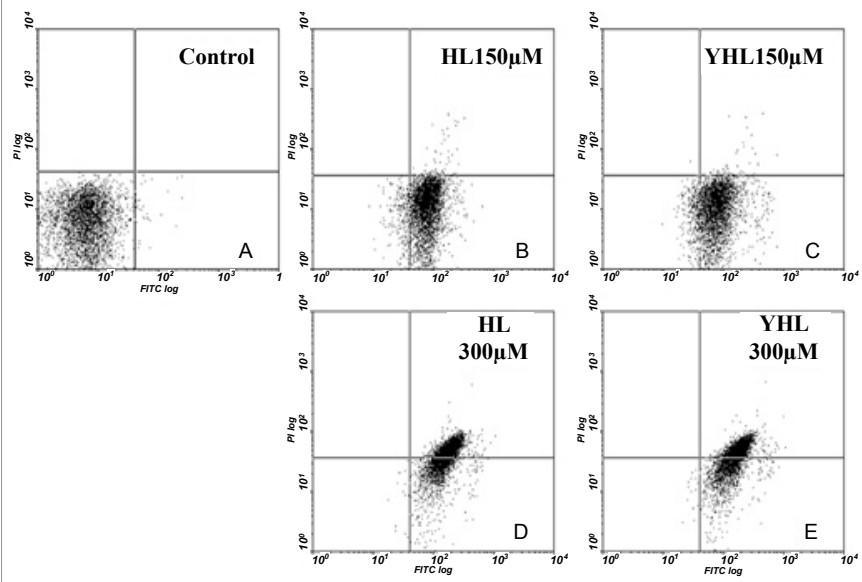

Figure 3: HL- and YHL- induce apoptosis in MHCC97L cells. MHCC97L cells were treated with $\mathrm{HL}$ and $\mathrm{YHL}$ for $24 \mathrm{hrs}$. Annexin V/PI double-staining was used for flow cytometry (FCM). A. control; B. HL extracts $150 \mu \mathrm{M}$; C. YHL extracts $150 \mu \mathrm{M}$; D. HL extracts $300 \mu \mathrm{M}$; E. YHL extracts $300 \mu \mathrm{M}$.

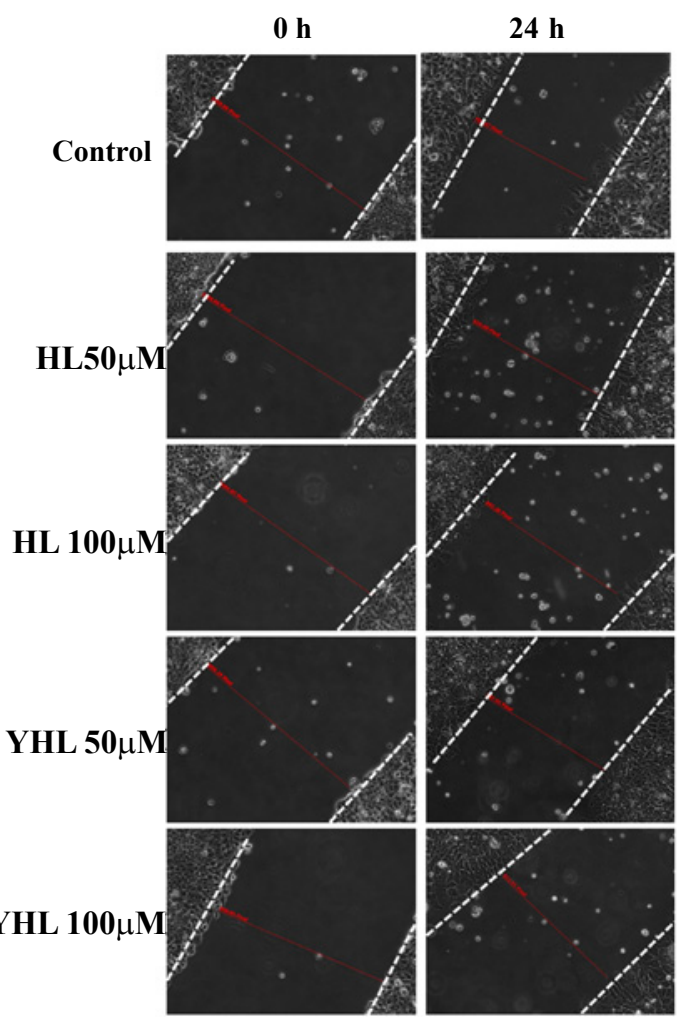

Figure 4: Anti-metastasis of agents in different time points. MHCC97L cells were treated with $\mathrm{HL}$ and $\mathrm{YHL}$ at different concentrations for 0 and $24 \mathrm{hrs}$. Distance between the two opposite edges wound was captured and recorded at the relative time points. There is no significant difference between two herbal extracts.

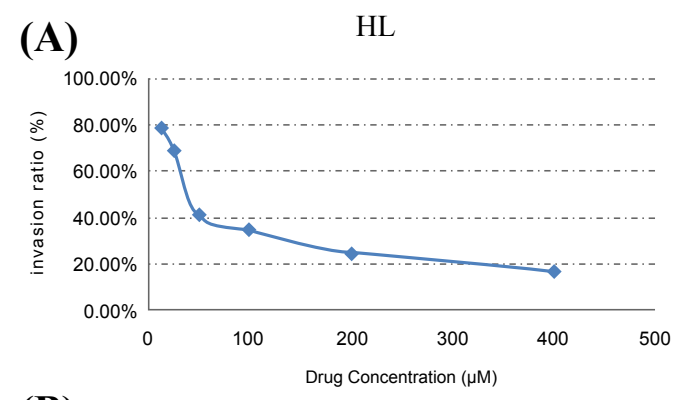

(B)

YHL

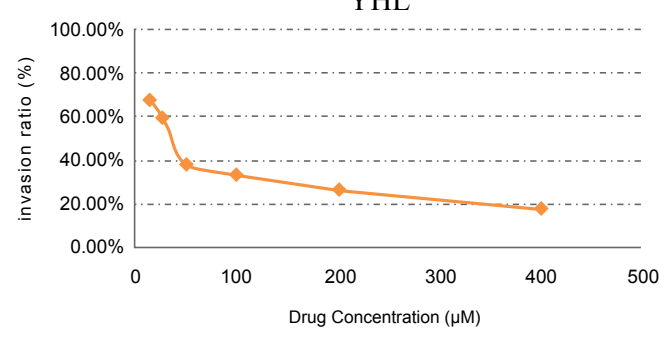

Figure 5: Comparison of invasion inhibitory between $\mathrm{HL}$ and $\mathrm{YHL}$ in 24hrs. $\mathrm{HL}$ and $\mathrm{YHL}$ extracts at the concentration of $12.5,25,50,100,200$, and $400 \mu \mathrm{M}$ were added to cell suspension and incubated for 24 hours at $37,5 \% \mathrm{CO}_{2}$. Data indicated there is no difference between $\mathrm{HL}$ and $\mathrm{YHL}$ extracts on invasion of MHCC97L cells.

invasion chamber assay indicated HL and YHL showed no difference in their capability to suppress cell invasion.

In conclusion, HL and YHL share great similarities in both chemical composition and inhibitory effect on HCC growth and metastasis. In addition, we also found that other ingredients in HL and YHL presented a synergetic interaction with berberine which increased the late effects on cancer (data not shown). This sheds light on the application of HL and YHL as HCC therapeutic agents and deserves further studies.

\section{Acknowledgements}

The study was financially supported by grants from the research council of the University of Hong Kong (Project Code: 10401764), The Research Grant Committee (RGC) of Hong Kong SAR of China (RGC General Research Fund Project Code: 10500362). The authors are grateful to Ms Oi Yee Chow, Ms Cindy Lee, Mr. Keith Wong, and Mr. Freddy Tsang for their technical support.

\section{References}

1. Tang J, Feng Y, Tsao S, Wang N, Curtain R, et al. (2009) Berberine and Coptidis rhizoma as novel antineoplastic agents: a review of traditional use and biomedical investigations. J Ethnopharmacol 126: 5-17.

2. Feng YB, Luo WQ, Zhu SQ (2008) [Explore new clinical application of Huanglian and corresponding compound prescriptions from their traditional use]. Zhongguo Zhong Yao Za Zhi 33: 1221-1225.

3. Yu FS, Yang JS, Lin HJ, Yu CS, Tan TW, et al. (2007) Berberine inhibits WEHI3 leukemia cells in vivo. In Vivo 21: 407-412.

4. Meeran SM, Katiyar S, Katiyar SK (2008) Berberine-induced apoptosis in human prostate cancer cells is initiated by reactive oxygen species generation. Toxicol Appl Pharmacol 229: 33-43.

5. Otsuka H, Fujimura H, Sawada T, Goto M (1981) [Studies on anti-inflammatory agents. II. Anti-inflammatory constituents from Rhizome of Coptis japonica Makino (author's transI)]. Yakugaku Zasshi 101: 883-890.

6. Kuo CL, Chi CW, Liu TY (2004) The anti-inflammatory potential of berberine in vitro and in vivo. Cancer Lett 203: 127-137. 
Citation: To C, Liew C, Wang X, Wang N, Feng Y (2012) Comparison of Components and Anti-Liver Cancer Activity In vitro between Huanglian and Yunlian. J Bioequiv Availab 4: 086-090. doi:10.4172/jbb.1000118

7. Feng $\mathrm{Y}$, Cheung KF, Wang N, Liu P, Nagamatsu T, et al. (2009) Chinese medicines as a resource for liver fibrosis treatment. Chin Med 4: 16

8. Kim HY, Shin HS, Park H, Kim YC, Yun YG, et al. (2008) In vitro inhibition of coronavirus replications by the traditionally used medicinal herbal extracts, Cimicifuga rhizoma, Meliae cortex, Coptidis rhizoma, and Phellodendron cortex. J Clin Virol 41: 122-128.

9. Kwon HA, Kwon YJ, Kwon DY, Lee JH (2008) Evaluation of antibacterial effects of a combination of Coptidis Rhizoma, Mume Fructus, and Schizandrae Fructus against Salmonella. Int J Food Microbiol 127: 180-183.

10. Hwang JM, Wang CJ, Chou FP, Tseng TH, Hsieh YS, et al. (2002) Inhibitory effect of berberine on tert-butyl hydroperoxide-induced oxidative damage in rat liver. Arch Toxicol 76: 664-670.

11. Ho YT, Lu CC, Yang JS, Chiang JH, Li TC, et al. (2009) Berberine induced apoptosis via promoting the expression of caspase-8, -9 and -3 , apoptosisinducing factor and endonuclease G in SCC-4 human tongue squamous carcinoma cancer cells. Anticancer Res 29: 4063-4070.

12. Auyeung KK, Ko JK (2009) Coptis chinensis inhibits hepatocellular carcinoma cell growth through nonsteroidal anti-inflammatory drug-activated gene activation. Int J Mol Med 24: 571-577.

13. Eom KS, Hong JM, Youn MJ, So HS, Park R, et al. (2008) Berberine induces G1 arrest and apoptosis in human glioblastoma T98G cells through mitochondrial/ caspases pathway. Biol Pharm Bull 31: 558-562.

14. Qin Y, Pang JY, Chen WH, Zhao ZZ, Liu L, et al. (2007) Inhibition of DNA topoisomerase I by natural and synthetic mono- and dimeric protoberberine alkaloids. Chem Biodivers 4: 481-487.

15. Liu J, He C, Zhou K, Wang J, Kang JX (2009) Coptis extracts enhance the anticancer effect of estrogen receptor antagonists on human breast cancer cells. Biochem Biophys Res Commun 378: 174-178.

16. Katiyar SK, Meeran SM, Katiyar N, Akhtar S (2009) p53 Cooperates berberineinduced growth inhibition and apoptosis of non-small cell human lung cancer cells in vitro and tumor xenograft growth in vivo. Mol Carcinog 48: 24-37.

17. Choi MS, Yuk DY, Oh JH, Jung HY, Han SB, et al. (2008) Berberine inhibits human neuroblastoma cell growth through induction of p53-dependent apoptosis. Anticancer Res 28: 3777-3784.

18. Remppis A, Bea F, Greten HJ, Buttler A, Wang H, et al. (2010) Rhizoma Coptidis inhibits LPS-induced MCP-1/CCL2 production in murine macrophages via an AP-1 and NFkappaB-dependent pathway. Mediators Inflamm 2010: 194896.

19. Pandey MK, Sung B, Kunnumakkara AB, Sethi G, Chaturvedi MM, et al. (2008) Berberine modifies cysteine 179 of IkappaBalpha kinase, suppresses nuclear factor-kappaB-regulated antiapoptotic gene products, and potentiates apoptosis. Cancer Res 68: 5370-5379.
20. Hsu WH, Hsieh YS, Kuo HC, Teng CY, Huang HI, et al. (2007) Berberine induces apoptosis in SW620 human colonic carcinoma cells through generation of reactive oxygen species and activation of JNK/p38 MAPK and FasL. Arch Toxicol 81: 719-728.

21. Zhu M, Wang N, Tsao S-W, Yuen M-F, Feng Y, et al. (2011) Up-regulation of microRNAs, miR21 and miR23a in human liver cancer cells treated with Coptidis rhizoma aqueous extract. Experimental and Therapeutic Medicine 2 27-32.

22. Wang N, Feng Y, Zhu M, Tsang CM, Man K, et al. (2010) Berberine induces autophagic cell death and mitochondrial apoptosis in liver cancer cells: the cellular mechanism. J Cell Biochem 111: 1426-1436

23. Committee C P (2005) China Pharmacopoeia (vol. I) Chemical Industry Press: 213.

24. Kuang HX (2000) Chinese Medicine Chemistry. China Press of Traditional Chinese Medicine.

25. Tsang CM, Lau EP, Di K, Cheung PY, Hau PM, et al. (2009) Berberine inhibits Rho GTPases and cell migration at low doses but induces G2 arrest and apoptosis at high doses in human cancer cells. Int J Mol Med 24: 131-138.

26. Chen J, Wang F, Liu J, Lee F S-C, Wang X, et al. (2008) Analysis of alkaloids in Coptis chinensis Franch by accelerated solvent extraction combined with ultra performance liquid chromatographic analysis with photodiode array and tandem mass spectrometry detections. Anal Chim Acta 21: 184-195.

27. Wang N, Feng Y, Lau EP, Tsang C, Ching Y, et al. (2010) F-actin reorganization and inactivation of rho signaling pathway involved in the inhibitory effect of Coptidis Rhizoma on hepatoma cell migration. Integr Cancer Ther 9: 354-364.

28. Han Z, Zheng Y, Chen N, Luan L, Zhou C, et al. (2008) Simultaneous determination of four alkaloids in Lindera aggregata by ultra-high-pressure liquid chromatography-tandem mass spectrometry. J Chromatogr A 1212: 7681.

29. Deng Y, Liao Q, Li S, Bi K, Pan B, et al. (2008) Simultaneous determination of berberine, palmatine and jatrorrhizine by liquid chromatography-tandem mass spectrometry in rat plasma and its application in a pharmacokinetic study after oral administration of coptis-evodia herb couple. Journal of Chromatography B 863: 195-205.

30. Sun J, Ma JS, Jin J, Wang HS, Wen QH, et al. (2006) [Qualitative and quantitative determination of the main components of huanglianjiedu decoction by HPLC-UV/MS]. Yao Xue Xue Bao 41: 380-384.

31. Yin L, Lu B, Qi Y, Xu L, Han X, et al. (2009) Simultaneous determination of 11 active components in two well-known traditional Chinese medicines by HPLC coupled with diode array detection for quality control. J Pharm Biomed Anal 49: 1101-1108.
Submit your next manuscript and get advantages of OMICS Group submissions

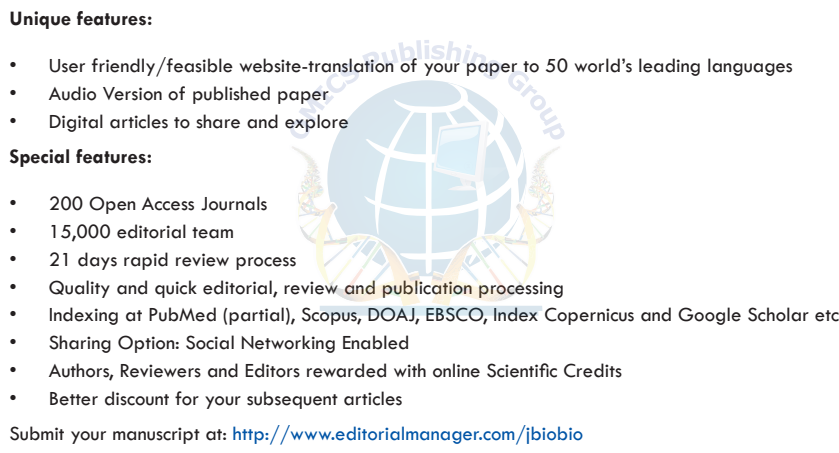

